\title{
Hazards Exposures and the Common Health and Safety Complaints Among Hospital Laundry Workers: A Comparative Study
}

\author{
Emmanuel Nosa Omoijiade ${ }^{1, \text { * }}$, Lucky Evbuomwan ${ }^{2}$ \\ ${ }^{1}$ Department of Environmental Health Sciences, University of Ibadan, Ibadan, Nigeria \\ ${ }^{2}$ Department of Microbiology, University of Benin, Benin City, Nigeria \\ Email address: \\ nossieomons@yahoo.com (E. N. Omoijiade), evbuomwanluckyl@gmail.com (L. Evbuomwan) \\ ${ }^{*}$ Corresponding author \\ To cite this article: \\ Emmanuel Nosa Omoijiade, Lucky Evbuomwan. Hazards Exposures and the Common Health and Safety Complaints Among Hospital \\ Laundry Workers: A Comparative Study. Journal of Health and Environmental Research. Vol. 5, No. 3, 2019, pp. 63-77. \\ doi: $10.11648 /$ j.jher.20190503.11
}

Received: July 8, 2019; Accepted: July 30, 2019; Published: September 10, 2019

\begin{abstract}
Healthcare workers are exposed to various hazards in their workplaces that pose threats to their health and safety, however, exposure depends on the job category and their work environment. In the healthcare facilities, occupational safety and health hazards can be grouped according to location or service offered. Contaminated laundry, noise, heat, lifting, sharps, slips, trips, falls and fire hazards are among those located in the laundry department. In industrial laundries, chemical exposure, injuries from sharps left in linen, slips from wet floors, and exposure to pathogens in contaminated linen are among the most common accidents. The purpose of the study was to provide information on the exposure of hospital laundry workers to previously identified workplace hazards, in order that appropriate interventions to minimize occupational risks due to workers exposures to hazards in the healthcare laundries would be established. Furthermore, it also provides information on the common health and safety complaints among laundry workers. The study adopted a comparative cross-sectional study design, conducted in hospitals with a laundry department in Benin, Nigeria. A survey was conducted as semi-structured questionnaires were issued to the study participants to obtain data on their exposure to different workplace hazards as well as on work-related injuries and diseases. Also, body mapping exercise was conducted to obtain workers' health information resulting from exposures to ergonomic hazards. All the respondents handled clean linen but only $74 \%$ handled dirty linen, while $62 \%$ handled soiled linen. In addition, respondents reported that they were exposed to sharps (62\%), ergonomic (40\%), illumination ( $2 \%)$, noise $(28 \%)$, electrical $(50 \%)$, heat $(38 \%)$ and chemical $(68 \%)$ hazards in the workplace. The common workplace injuries or illnesses reported were sharps injury (20\%), musculoskeletal pain $(92 \%)$, hearing disorder $(4 \%)$, burns $(8 \%)$, electric shocks (6\%), slips, trips, or falls $(28 \%)$ and cuts or bruises $(18 \%)$. The most common musculoskeletal complaints were that of the lower back (74\%), shoulders (42\%), upper back (34\%), and knee (34\%). Various types of hazards were identified in all the health facilities. Hospital laundry workers in both secondary and tertiary health facilities alike suffered from various adverse health and safety conditions due to exposure to occupational hazards in the workplace. It is recommended that laundry workers be frequently educated on the occupational health and safety risks associated with their job.
\end{abstract}

Keywords: Hazards Exposures, Hospital Laundry, Health Facilities, Laundry Workers, Accidents, Injuries, Health and Safety, Occupational Health

\section{Introduction}

Occupational hazards refer to factors in the workplace with a potential to cause harm, in terms of injury or ill health [1, 2]. Tens of thousands of people die from occupational illnesses, while hundreds of thousands of new cases of occupational diseases are diagnosed every year [3, 4]. Workers in various occupations are affected as a result of their exposure to different types and varying degrees of occupational hazards. 
Hazards are classified as: physical (including noise, vibration, radiation, extremes of temperature, etc.), ergonomic (mechanical), chemical (solid, liquid, and vapors), biological (including bacteria, viruses, fungi, etc.), and psychosocial (including psychological and social stress factors). When workers are exposed to any of these hazards, it may result in occupational diseases, work accidents or a combination of both [5].

Hazards are inherent in every industrial and economic sector [6], just as every activity possesses inherent hazards. These hazards, if ignored, pose significant health and safety risks to individuals who get exposed to them [7].

The health sector also possesses a range of hazards with a large number of workers from different professional streams exposed to these hazards [8]. Hospitals are highly hazardous [9], as hospital workers are exposed to a variety of occupational hazards that may threaten their health and safety.

Globally, tens of millions of workers are employed in healthcare facilities (HCFs), offering a variety of services. HCFs are classified as high-risk workplaces $[10,11]$, which is characterized by a high level of exposure to hazardous agents (physical, chemical, biological, ergonomic and psychosocial) that significantly endangers the health and life of workers [8].

Healthcare workers (HCWs) are exposed to various health and safety hazards on a daily basis including, biological hazards, such as Hepatitis, Human Immunodeficiency Virus/Acquired Immunodeficiency Syndrome; chemical hazards, such as glutaraldehyde, ethylene oxide; physical hazards, such as radiation, slips, trips and falls; ergonomic hazards, such as heavy lifting; psychosocial hazards, such as shift work, violence and stress $[12,13]$. It is however noted that exposure of the healthcare worker $(\mathrm{HCW})$ to hazardous agents is dependent upon their job category and work environment $[14,15]$.

Occupational health and safety (OHS) hazards in healthcare facilities can be grouped according to location or service offered. Contaminated laundry, heat, noise, sharps, lifting, slips, falls, trips and fire hazards are among those located in the laundry department [12]. However, in industrial laundries, the most common accidents involve chemical exposure, injuries from sharp objects left in linen, slips from wet floors, exposure to pathogens in contaminated linen, among others [16].

Of all the potential hazards in the healthcare laundry environment, sharps injuries and bloodborne pathogen exposures can be some of the most injurious to workers in terms of long-term treatment required [16].

A study conducted by Borg and Portelli in Manila, suggested that continuous exposure to contaminated hospital linen may cause a significant rise in the possibility of infection with hepatitis A [8], and was supported after a study carried out by Keeffe [17]. An estimated 20 to $40 \%$ of healthcare-associated infections (HAIs) have been attributed to cross-infection via the hands of health care workers (HCWs), who have become contaminated from direct contact with the patient or indirectly by touching contaminated hospital environmental surfaces [18]. Orji et al opined that needle stick injuries were the commonest occupational health hazard reported from a Nigerian teaching hospital [19]. World Health Organization (WHO) estimated that there are approximately 3 million cases of needle stick injury (NSI) in healthcare workers each year, with $90 \%$ of these occurring in developing countries, resulting in $40 \%$ of hepatitis B and C cases among HCWs worldwide [20].

Adverse effects of cleaning products on skin, such as occupational hand dermatitis, have also been reported by some studies on hospital cleaning workers [21-23]. Results from epidemiological investigations support the hypothesis that exposure to cleaning products is related to the development and/or exacerbation of respiratory symptoms, including asthma [24-31]. Findings from some studies have shown that bleach can be responsible for asthma symptoms among domestic cleaners [28, 32]. Complexing agents (substances capable of forming a complex compound with another material in solution) such as EDTA (Ethylene Diamine Tetra Acetic Acid) can cause eye or skin irritation.

Physical hazards in the general working environment that are also encountered in the hospital environment include temperature, illumination, noise, vibration, slips, trips and falls, changes in atmospheric pressure, and ionizing and nonionizing radiation [5, 33-38].

Occupational noise is present in hospitals, mainly in hospital laundries where continuous exposition to high levels of sound pressure may bring about permanent changes in workers' hearing threshold. In a research held at the Clinicas Hospital of Medical School from Universidade Federal de Goiás, the mapping of hospital noise evidenced averaged $75 \mathrm{~dB}$ in all hospital settings, and in the laundry, the noise level found was $91 \mathrm{~dB}$ in the morning period and $90 \mathrm{~dB}$ in the evening period. The authors verified that $31.4 \%$ of the workers presented characteristic audiometries for noiseinduced hearing loss [39].

Laundry workers are also at risk of musculoskeletal disorders [40]. Laundry workers spend long periods on their feet, and are regularly required to lift heavy loads [41]. Muslim et. al showed in a research that in every single activity of laundry workers in Indonesia, the positions were not ergonomic [42]. Based on the posture assessment in her research, she concluded that there is need for improvement in the laundry workers' posture. The workers complained primarily of pains in the waist and arm.

Tasks carried out by workers in the laundry of a large general hospital put them at risk of lower back and shoulders injuries. The tasks included a combination of excessive forward bending to lift dry and wet linen, forceful exertion, and work in awkward postures [43].

According to Tseko and Pilane, occupational-related human immunodeficiency virus (HIV) transmission among healthcare workers results mostly from needle pricks, blood and body fluid splashes [44]. World Health Organization reported that among the 35 million health workers worldwide, about 3 million sustain percutaneous exposures 
via needle-stick injuries to blood borne pathogens each year, including 2 million to hepatitis B virus (HBV), 0.9 million to hepatitis $\mathrm{C}$ virus (HCV) and 170,000 to human immune deficiency virus (HIV) [18].

Kumar et al. in 2014 carried out a study which identified various occupational hazards associated with hospital laundry operations [45]. Hence, the purpose of the study was to provide information on the exposure of hospital laundry workers to previously identified workplace hazards, in order that appropriate interventions to minimize occupational risks due to workers exposures to hazards in the healthcare laundries would be established. Furthermore, it also provides information on the common health and safety complaints among laundry workers.

The study objectives were to assess the exposure of workers to hazards in the hospital laundry, the common health complaints, accidents and injuries of hospital laundry workers, as well as to make a comparison among the different health facilities in the Benin metropolis.

\section{Materials and Methods}

\subsection{Study Design}

This study adopted a comparative cross-sectional study design.

\subsection{Study Area}

The study was conducted in hospitals with a laundry department in Benin-City. They include University of Benin Teaching Hospital, Central Hospital Benin, Stella Obasanjo Hospital, St. Philomena Catholic Hospital, Faith Medical Complex and Ihenyen Hospital.

The University of Benin Teaching Hospital (UBTH) is a federal tertiary health facility located on the Benin-Lagos expressway in Ugbowo, Benin. Established in 1973, it boasts facilities to accommodate over 500 in-patients.

While Stella Obasanjo Hospital (SOH) and Central
Hospital Benin (CHB) are secondary healthcare facilities run by the state government, St. Philomena Catholic Hospital (SPCH), Ihenyen Hospital (IH), and Faith Medical Complex (FMC) are secondary care health facilities, owned and run by private groups or individuals, providing various healthcare services.

\subsection{Study Population}

The study was carried out among the hospital laundry workers. 42 respondents per group was the minimum sample size required as calculated based on the formula for sample size estimation of two proportions illustrated below:

$$
\mathrm{N}=\frac{\left(Z_{a}+Z_{b}\right)^{2}\left(p_{1} q_{1}+p_{2} q_{2}\right)}{\left(p_{1}-p_{2}\right)^{2}}
$$

Where; $\mathrm{N}=$ sample size per group,

$\mathrm{P}=$ proportion of the attribute,

$\mathrm{q}=$ complement of ' $\mathrm{p}$ ',

$Z_{\mathrm{a}}=1.96(95 \%$ confidence level $)$,

$\mathrm{Z}_{\mathrm{b}}=0.84$ (80\% power),

$\mathrm{P}_{1}=0.646$ [46],

$\mathrm{P}_{2}=0.342$ [47].

Hence, a minimum of 84 respondents was required for the study. Due to limited population size however, there was no need to take a sample, as the total population was used.

Of the 54 eligible participants, only 50 respondents were present and gave their consent to participate in the study; a $92.6 \%$ response rate (table 1 ).

\subsubsection{Inclusion Criterion}

i. Healthcare laundry workers who gave their consent to participate.

\subsubsection{Exclusion Criteria}

i. Healthcare laundry workers absent while the study was conducted.

ii. Workers who declined participation in the study.

iii.Laundry workers in the tailoring unit of the department.

Table 1. Characteristics of the health facilities studied.

\begin{tabular}{lllll}
\hline S/N & Ownership & Type of health facility & Number of laundry workers & Number of respondents \\
\hline 1 & Government & Tertiary & 35 & 31 \\
2 & Government & Secondary & 3 & 3 \\
3 & Government & Secondary & 2 & 6 \\
4 & Private & Secondary & 4 & 4 \\
5 & Private & Secondary & 4 & 4 \\
6 & Private & Secondary & 54 & 50 \\
TOTAL & & & 4 \\
\hline
\end{tabular}

\subsection{Data Instruments}

A survey was conducted as semi-structured questionnaires were issued to the study participants. It sought to provide data on their exposure to different workplace hazards, workrelated injuries and health complaints. Also, a body mapping exercise was adapted from a DHHS-NIOSH publication [48], and used to obtain the health information of the study participants as a result of exposure to ergonomic hazards. It provided information on; body part (s) with pain or discomfort, level of pain or discomfort, and duration of episodes. Interviews were conducted to obtain data from respondents who were not literate.

\subsection{Ethics Approval and Consent to Participate}

The Edo State Hospital Management Board, the administrators of all the private hospitals included in the study (SPCH, FMC and IH), as well as the University of 
Benin Teaching Hospital ethical committee, issued ethical clearance and approval for the study to be conducted in their facilities.

Furthermore, respondents were duly informed on all the processes involved in the research and required to give their consent before participation in the study. Also questionnaires did not require respondents to provide information on their identity thereby maintaining the confidentiality of respondents' identities. Respondents were treated equally, so that there was no maleficence from respondents.

\subsection{Data Management and Analysis}

Data was entered into the Statistical package for social science version 20 (SPSS 20) which was used to manage and analyze the data. Descriptive statistics was used to summarize data on the socio-demographic characteristics, exposure of respondents to workplace hazards, and the common health complaints of the workers, using frequency tables, bar graphs and pie charts.

Furthermore, a relationship hazard exposure of respondents and health facility indices, as well as between common health complaints and health facility indices, was checked via chi-square analysis. A 95\% confidence level was used, so that a $\mathrm{P}$-value less than $0.05(\mathrm{P}<0.05)$ meant a rejection of the null hypothesis, subsequently stating a significant relationship between the tested variables.

\section{Results}

\subsection{Socio-Demographic Characteristics}

The study population was largely female (60\%). Respondents' mean age was $47.66 \pm 11.19$ years, with most respondents $(26 \%)$ between the ages of 41 and 50 years. However, the government tertiary hospitals had more males $(54.8 \%)$ than females $(45.2 \%)$, while most of the respondents in the private secondary $(28.6 \%)$ and government secondary $(40 \%)$ were between the ages of 51 and 60 years. This is presented in table 2 .

As presented in table 3 , the study also revealed a relationship between the sex of respondents and the health facility types $(p=0.006)$ and hospital categories $(p=0.023)$. Tables 4 and 5 show that there was no statistically significant difference in the age of respondents between the health facility types $(p=0.285)$ and among the hospital categories $(\mathrm{p}=0.324)$ respectively.

As shown in table 2 , most of the respondents in the study $(40 \%)$ had received up to secondary school education. Among the various hospital categories, most of the respondents in private secondary $(35.7 \%)$ and government secondary $(40 \%)$ had received up to primary school education only.

As presented in table 3, a P-value of 0.15 which showed no association was observed between educational qualification and hospital categories, but the P-value dropped to 0.025 , which shows an association when educational qualification was compared between the types of health facilities.

Respondents' work experience in the healthcare laundry averaged $8.48 \pm 7.72$ years, though, most of them (50\%) had worked there less than 5 years and were employed on a permanent basis $(82 \%)$. Among the various hospital categories, most $(35.5 \%)$ of the respondents in government tertiary hospital laundry had working experience between 5 and 10 years, while most $(80 \%)$ of those in government secondary were employed on a contract basis. Table 2 illustrates this.

In addition, the study also revealed as shown in tables 4 and 5, that there was a significant difference in the length of work experience between the health facility types $(p=0.024)$ and among the various hospital categories $(p=0.021)$ respectively. Moreover, a P-value of 0.66 which showed no association was observed between mode of employment and health facility type, but the P-value dropped to 0.00 , which shows an association when mode of employment was compared among the various hospital categories (table 3 ).

Table 2. Socio-demographic characteristics of respondents.

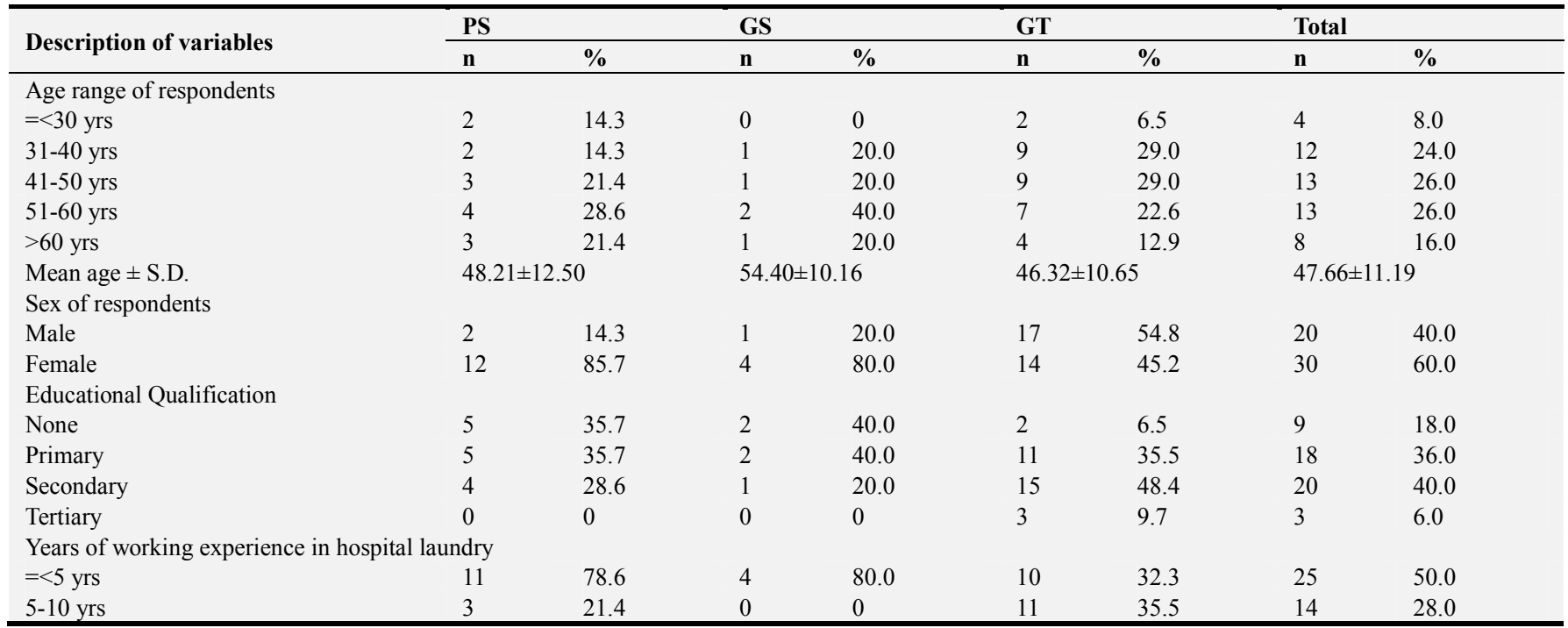




\begin{tabular}{|c|c|c|c|c|c|c|c|c|}
\hline \multirow{2}{*}{ Description of variables } & \multicolumn{2}{|l|}{ PS } & \multicolumn{2}{|c|}{ GS } & \multicolumn{2}{|c|}{ GT } & \multicolumn{2}{|c|}{ Total } \\
\hline & n & $\%$ & n & $\%$ & $\mathbf{n}$ & $\%$ & n & $\%$ \\
\hline $11-15$ yrs & 0 & 0 & 0 & 0 & 2 & 6.5 & 2 & 4.0 \\
\hline $15-20 \mathrm{yrs}$ & 0 & 0 & 0 & 0 & 5 & 16.1 & 5 & 10.0 \\
\hline$>20 \mathrm{yrs}$ & 0 & 0 & 1 & 20.0 & 3 & 9.7 & 4 & 8.0 \\
\hline Mean \pm S.D. & \multicolumn{2}{|c|}{$3.71 \pm 2.525$} & \multicolumn{2}{|c|}{$10.00 \pm 14.00$} & \multicolumn{2}{|c|}{$10.39 \pm 7.32$} & \multicolumn{2}{|c|}{$8.48 \pm 7.72$} \\
\hline \multicolumn{9}{|l|}{ Mode of employment } \\
\hline Permanent & 14 & 100 & 1 & 20.0 & 26 & 83.9 & 41 & 82.0 \\
\hline Contract & 0 & 0 & 4 & 80.0 & 5 & 16.1 & 9 & 18.0 \\
\hline
\end{tabular}

where; PS=Private Secondary,

GS=Government Secondary, and

GT $=$ Government Tertiary.

Table 3. Measure of association between health facility indices and socio-demographic characteristics.

\begin{tabular}{llll}
\hline \multirow{2}{*}{ Description of variables } & \multicolumn{2}{l}{ Type of health facility } & \multicolumn{2}{c}{ Hospital category } \\
\cline { 2 - 4 } & $\mathbf{X}^{\mathbf{2}}$ & P-value & $\mathbf{X}^{\mathbf{2}}$ \\
\hline Sex of respondents & 7.484 & 0.006 & 7.535 \\
Educational qualification & 9.324 & 0.025 & 9.448 \\
Mode of employment & 0.193 & 0.660 & 0.023 \\
\hline
\end{tabular}

Table 4. Independent samples T-test of socio-demographic characteristics between health facility types.

\begin{tabular}{lllll}
\hline \multirow{2}{*}{ Description of variables } & T & P-value & 95\% Confidence Interval of the Difference & Lower \\
\hline Age of respondents & & 1.082 & 0.285 & -3.023 \\
Years of work experience in hospital laundry & -2.331 & 0.024 & -9.348 & 10.062 \\
\hline
\end{tabular}

Table 5. ANOVA of socio-demographic characteristics among the various hospital categories.

\begin{tabular}{lll}
\hline Description of variables & F & P-value \\
\hline Age of respondents & 1.153 \\
Years of work experience in the hospital laundry & 4.197 \\
\hline
\end{tabular}

\subsection{Job Tasks of Respondents}

As illustrated in figure 1 , labeling of clean linen for delivery was carried out by only 2 (4\%) respondents, who worked in the tertiary healthcare laundry, as labeling was not carried out in the secondary healthcare laundries.

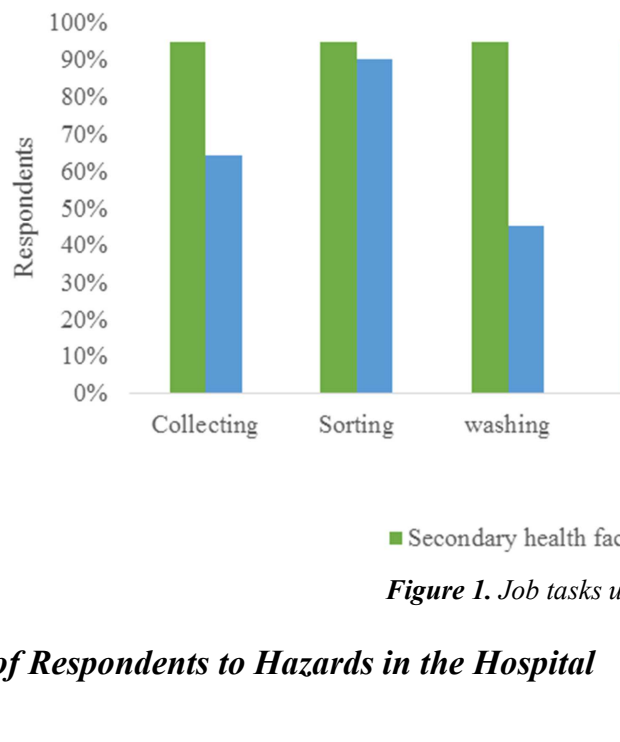
in the past year while carrying out their job tasks (figure 2), with no observed association between sharps exposure and hospital categories $(p=0.279)$ and the health facility types
Respondents (62\%) reported that they came across sharps

\subsection{Exposure of Respondents to Hazards in the Hospital Laundry}

Also, few respondents $(28 \%)$ were involved in ironing of laundry, while most of them were involved in the sorting of used laundry for washing (92\%) and the folding of washed, dried and ironed laundry $(78 \%)$.

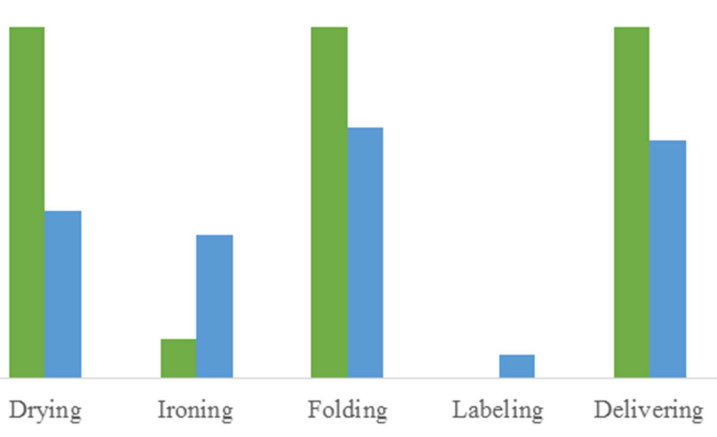

Job Tasks

\section{- Tertiary health facility}

$(\mathrm{p}=0.936)($ table 6$)$.

Respondents (40\%) reported that they did not carry out their job tasks in a comfortable posture as presented in figure 2. While all the respondents in private secondary and government secondary hospitals reported that they did not carry out their job tasks in a comfortable posture, only $3.2 \%$ of respondents in the government tertiary hospital reported 
so. An association between ergonomic hazard exposure and health facility indices was observed $(\mathrm{p}=0.000)$ as presented in table 6.

Only $2 \%$ of respondents reported that they were unable to see details of their workplace clearly while carrying out their job tasks as presented in figure 2, with no observed association between illumination hazard exposure and health facility types $(p=0.429)$ and hospital categories $(p=0.731)$ as presented in table 6 .

Respondents (28\%) reported that they were unable to communicate easily while carrying out their job tasks (figure 2). While none of the respondents in private secondary and government secondary hospitals reported that they were unable to communicate easily while carrying out their job tasks, $45.2 \%$ of respondents in the government tertiary hospital reported otherwise. An association between noise hazard exposure and hospital facility types $(p=0.001)$ and hospital categories $(p=0.003)$ was observed, as presented in table 6 .

As presented in figure 2, respondents (68\%) reported that they made use of chemicals while carrying out their job tasks, however, among the various hospital categories, 51.6\% of respondents in the government tertiary hospital, $80 \%$ of those in government secondary hospitals and all the respondents in private secondary hospitals reported so. An association between chemical hazard exposure and hospital facility types $(p=0.002)$ and hospital categories $(p=0.005)$ was observed, as presented in table 6 .

As presented in figure 2, respondents (38\%) reported that equipment which released heat was present in their workspace, however, among the various hospital categories, $54.8 \%$ of respondents in the government tertiary hospital, $20 \%$ of those in government secondary hospitals and $7.1 \%$ of respondents in private secondary hospitals reported so. An association between heat hazard exposure and hospital facility types $(p=0.002)$ and hospital categories $(p=0.006)$ was observed, as presented in table 6 .

Respondents (50\%) reported that electrical equipment was present in their work-space as presented in figure 2, with no observed association between electrical hazard exposure and hospital categories $(\mathrm{p}=0.678)$ and the health facility types $(\mathrm{p}=0.382)$ as presented in table 6 .

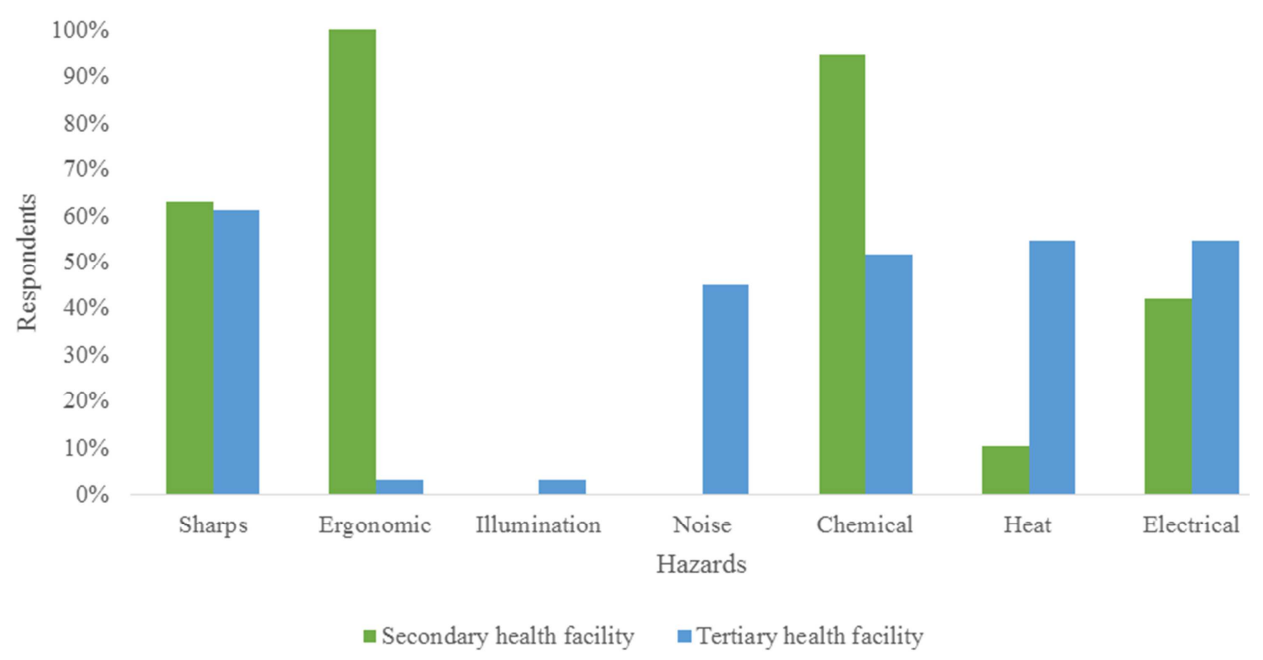

Figure 2. Exposure of respondents to hazards in the hospital laundry.

Table 6. Measure of association among health facility indices and hazards exposure.

\begin{tabular}{|c|c|c|c|c|}
\hline \multirow{2}{*}{ Description of variables } & \multicolumn{2}{|c|}{ Type of health facility } & \multicolumn{2}{|c|}{ Hospital category } \\
\hline & $\mathrm{X}^{2}$ & P-value & $\mathrm{X}^{2}$ & P-value \\
\hline Sharps & 0.007 & 0.936 & 2.551 & 0.279 \\
\hline Ergonomic hazard & 45.968 & 0.000 & 45.968 & 0.000 \\
\hline Illumination hazard & 0.625 & 0.429 & 0.625 & 0.731 \\
\hline Noise hazard & 11.918 & 0.001 & 11.918 & 0.003 \\
\hline Chemical hazard & 10.068 & 0.002 & 10.745 & 0.005 \\
\hline Heat hazard & 9.818 & 0.002 & 10.076 & 0.006 \\
\hline Electrical hazard & 0.764 & 0.382 & 0.776 & 0.678 \\
\hline
\end{tabular}

\subsection{Exposure of Respondents to Biological Hazards in Linen}

All the respondents handled clean linen, while $74 \%$ handled dirty linen and $62 \%$ handled soiled linen, as presented in figure 3 .

Among the various hospital categories, all the respondents in private secondary hospitals, $80 \%$ and $61.3 \%$ of those in government secondary hospitals and government tertiary hospital handled dirty linen respectively, while $57.1 \%, 80 \%$ and $61.3 \%$ of respondents in private secondary hospitals, government secondary hospitals and government tertiary hospital handled soiled linen respectively. 


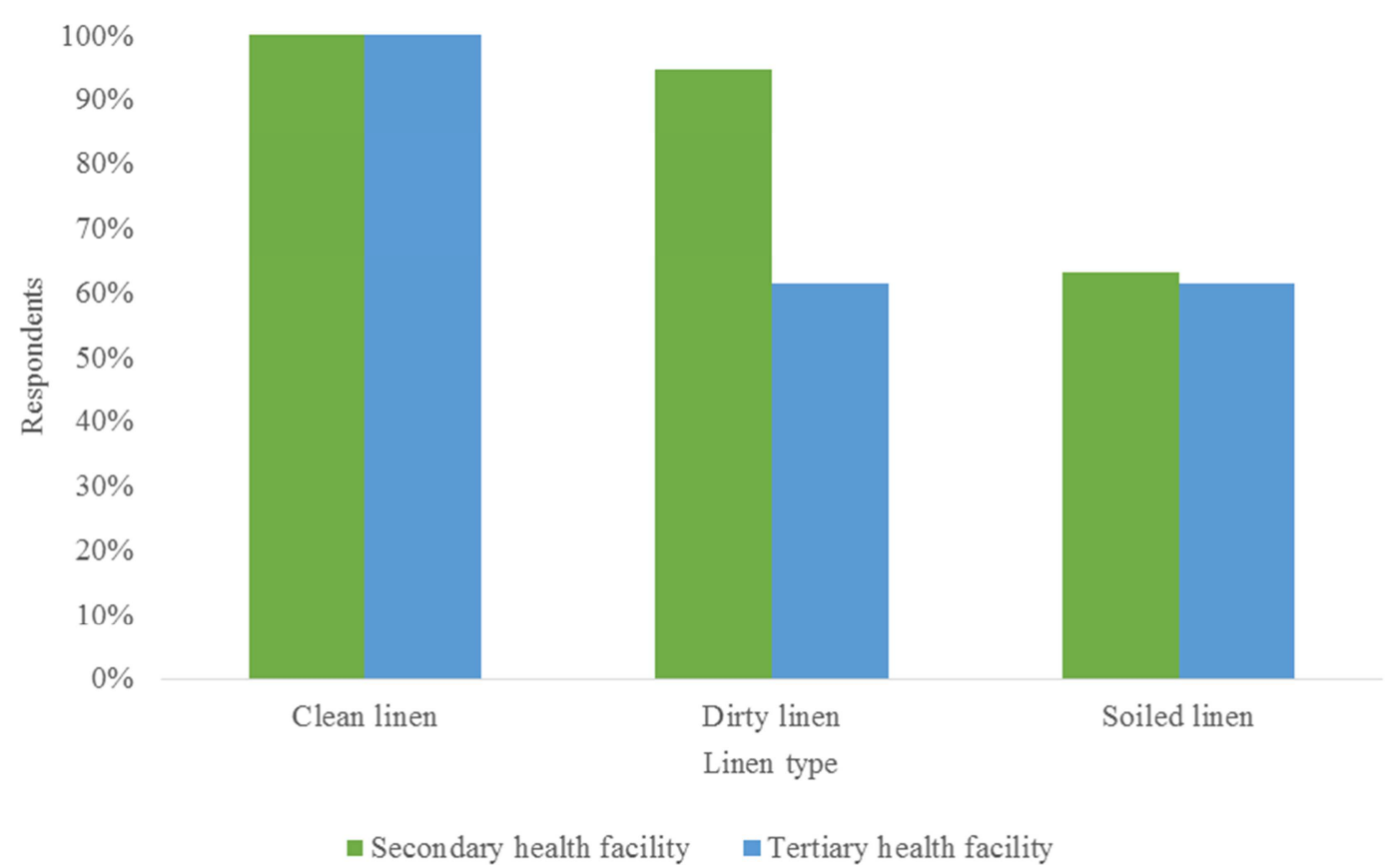

Figure 3. Exposure of respondents to microbiological hazards in linen.

\subsection{Common Adverse Health and Safety Effects on Respondents}

Respondents (20\%) reported that they had had at least one needle stick injury while carrying out their job tasks in the past year (Figure 4). However, among the various hospital categories, none of the respondents in private secondary, $60 \%$ of those in government secondary and $22.6 \%$ of those in government tertiary hospital reported that they had had at least one needle stick injury in the past year. No association between sharps injury and health facility type was observed $(p=0.560)$, however, there was an observed association between sharps injury among the various hospital categories $(\mathrm{p}=0.013)$ (Table 7).

Respondents (92\%) reported that they had had musculoskeletal pains in at least one part of their body while carrying out their job tasks in the past year, as presented in Figure 4. While all the respondents in the government secondary hospitals reported that they had had musculoskeletal pains in at least one part of their body in the past year, only $90.3 \%$ of respondents in the government tertiary and $92.9 \%$ of respondents in the private secondary hospitals reported so. No association between musculoskeletal pains and health facility types $(p=0.577)$ and hospital categories $(\mathrm{p}=0.753)$ was observed, as presented in Table 7.

As presented in Figure 4, only $6.5 \%$ of respondents in the government tertiary hospital reported that they had had hearing pains or disorder while carrying out their job tasks in the past year, with no observed association between hearing pains or disorder and health facility types $(p=0.258)$ and hospital categories $(\mathrm{p}=0.528)$ (Table 7).

Respondents $(8 \%)$ reported that they had had burns while carrying out their job tasks in the past year (Figure 4). While none of the respondents in private secondary reported that they had had burns in the past year, $9.7 \%$ of respondents in the government tertiary and $20 \%$ of those in the government secondary hospitals reported so. As presented in Table 7, no association between burns and hospital facility types $(p=0.577)$ and hospital categories $(p=0.314)$ was observed.

As presented in Figure 4, only $9.7 \%$ of respondents in the government tertiary hospital reported that they had had electric shocks while carrying out their job tasks in the past year, with no observed association between electrical shocks and health facility types $(\mathrm{p}=0.162)$ and hospital categories $(\mathrm{p}=0.376)$ (Table 7).

Respondents (28\%) reported that they had slipped, tripped or fallen while carrying out their job tasks in the past year (Figure 4). While all the respondents in the government secondary hospitals reported that they had slipped, tripped or fallen in the past year, only $12.9 \%$ of respondents in the government tertiary and $35.7 \%$ of respondents in the private secondary hospitals reported so. As presented in Table 7, an association between slips, trips or falls and health facility types $(p=0.002)$ and hospital categories $(p=0.000)$ was observed.

Only $29 \%$ of respondents in the government tertiary hospital reported that they had had cuts or bruises while carrying out their job tasks in the past year (Figure 4), with an observed association between cuts or bruises and health facility types $(p=0.009)$ and hospital categories $(p=0.035)$ (Table 7).

All of the respondents reported that they had neither had hand dermatitis nor breathing difficulty or asthmatic symptoms while carrying out their job tasks in the past year. 


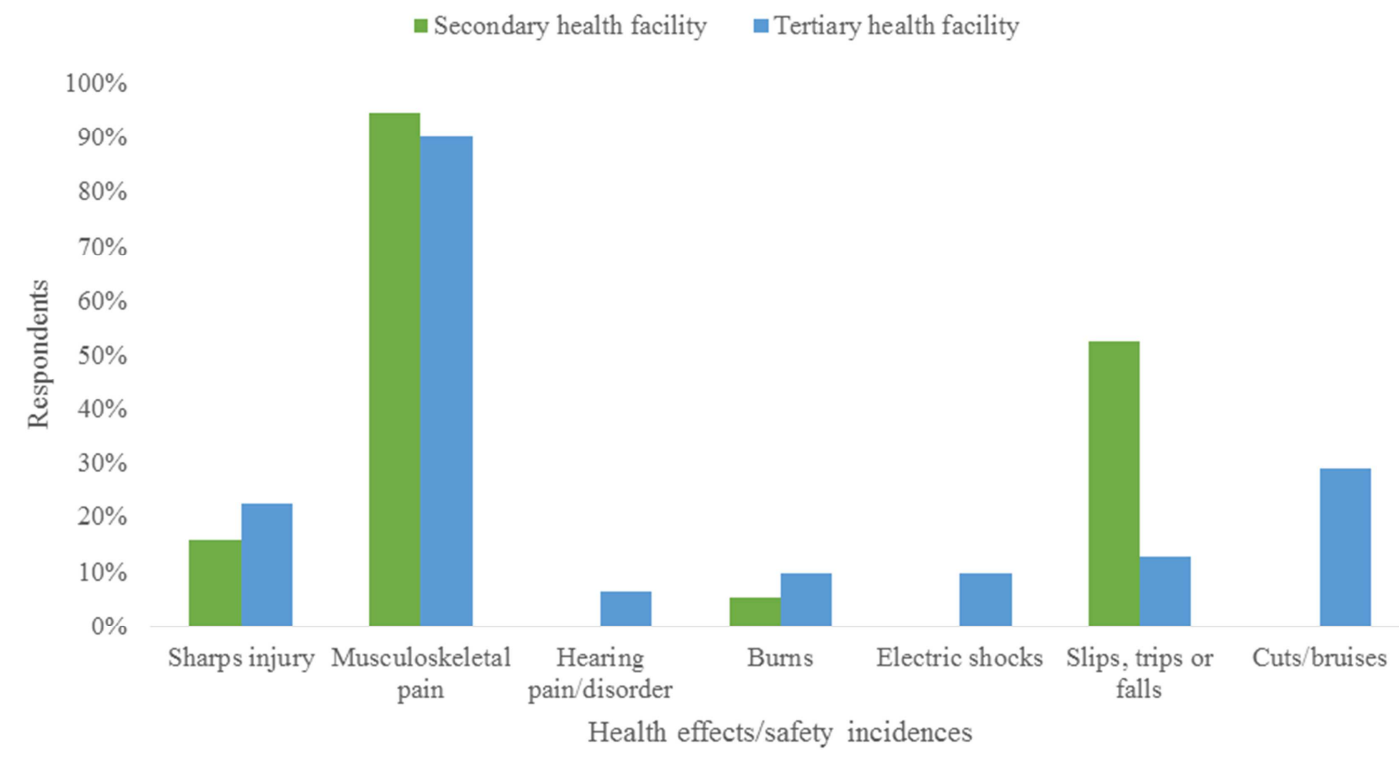

Figure 4. Common adverse health and safety effects on respondents.

Table 7. Measure of association among health facility indices and common health complaints, accidents and injuries.

\begin{tabular}{lllll}
\hline \multirow{2}{*}{ Description of variables } & \multicolumn{2}{l}{ Type of health facility } & Hospital category & P-value \\
\cline { 2 - 5 } & $\mathbf{X}^{\mathbf{2}}$ & $\mathbf{P}$-value & $\mathbf{X}^{\mathbf{2}}$ & 0.013 \\
\hline Sharps injury & 0.340 & 0.560 & 8.629 & 0.753 \\
Musculoskeletal pain & 0.312 & 0.577 & 0.567 & 0.528 \\
Hearing pain or disorder & 1.277 & 0.258 & 2.277 & 0.314 \\
Burns & 0.312 & 0.577 & 1.956 & 0.376 \\
Electric shocks & 1.956 & 0.162 & 16.775 & 0.000 \\
Slips, trips or falls & 9.223 & 0.002 & 6.727 & 0.035 \\
Cuts/bruises & 6.727 & 0.009 & & \\
\hline
\end{tabular}

\subsection{Musculoskeletal Complaints and Severity of Pain Among Respondents}

Respondents $(26 \%)$ reported that they suffered from pains in the neck region while carrying out their job tasks (Figure 5). However among the various hospital categories, $28.6 \%$ of the respondents in private secondary, $80 \%$ of those in government secondary and $16.1 \%$ of those in government tertiary hospital reported so. There was an observed association between pains in the neck region and health facility type $(\mathrm{p}=0.042)$, as well as among the various hospital categories $(\mathrm{p}=0.010)$ (Table 8$)$.

Respondents $(42 \%)$ reported that they suffered from pains in the shoulder region while carrying out their job tasks (Figure 5). While $85.7 \%$ of respondents in the private secondary and $60 \%$ of respondents in the government secondary hospitals reported that they suffered from pains in the shoulder region while carrying out their job tasks, only $19.3 \%$ of respondents in the government tertiary hospitals reported so. An association between pains in the shoulder region and health facility indices $(\mathrm{p}=0.000)$ was observed (Table 8).

Respondents (34\%) reported that they suffered from pains in the upper back region while carrying out their job tasks (Figure 5). However among the various hospital categories, $50 \%$ of the respondents in private secondary, $20 \%$ of those in government secondary and $29 \%$ of those in government tertiary hospital reported so. There was no observed association between pains in the upper back region and health facility type $(\mathrm{p}=0.344)$, as well as among the various hospital categories $(\mathrm{p}=0.305)$ (Table 8$)$.

Respondents (18\%) reported that they suffered from pains in the elbow/fore arm region while carrying out their job tasks (Figure 5). Among the various hospital categories, $14.3 \%$ of respondents in the private secondary, $40 \%$ of respondents in the government secondary and $16.1 \%$ of respondents in the government tertiary hospitals reported that they suffered from pains in the elbow/fore arm region while carrying out their job tasks. No association was observed between pains in the elbow/fore arm region and health facility type $(\mathrm{p}=0.660)$, as well as among the various hospital categories $(\mathrm{p}=0.398)$ (Table 8$)$.

Respondents $(20 \%)$ reported that they suffered from pains in the wrist/hand region while carrying out their job tasks (Figure 5). However among the various hospital categories, $14.3 \%$ of the respondents in private secondary, $80 \%$ of those in government secondary and $12.9 \%$ of those in government tertiary hospital reported so. There was no observed association between pains in the wrist/hand region and health facility type $(p=0.109)$, whereas an association was observed among the various hospital categories $(\mathrm{p}=0.002)$ (Table 8).

Respondents (18\%) reported that they suffered from pains 
in the fingers while carrying out their job tasks (Figure 5). Among the various hospital categories, $14.3 \%$ of respondents in the private secondary, $80 \%$ of respondents in the government secondary and $9.7 \%$ of respondents in the government tertiary hospitals reported that they suffered from pains in the fingers while carrying out their job tasks. There was no observed association between pains in the fingers and health facility type $(\mathrm{p}=0.050)$, whereas an association was observed among the various hospital categories $(p=0.001)$ (Table 8).

Respondents (74\%) reported that they suffered from pains in the lower back region while carrying out their job tasks (Figure 5). However among the various hospital categories, $85.7 \%$ of the respondents in private secondary, all of those in government secondary and $64.5 \%$ of those in government tertiary hospital reported so. There was no observed association between pains in the lower back region and health facility type $(\mathrm{p}=0.051)$, as well as among the various hospital categories $(\mathrm{p}=0.122)$ (Table 8$)$.

Only $19.3 \%$ of respondents in the government tertiary hospitals reported that they suffered from pains in the hip/thigh region while carrying out their job tasks (Figure 5). There was an observed association between pains in the hip/thigh region and health facility type $(\mathrm{p}=0.041)$, whereas no association was observed among the various hospital categories $(\mathrm{p}=0.124)$ (Table 8$)$.
Respondents (34\%) reported that they suffered from pains in the knee region while carrying out their job tasks (Figure 5). However among the various hospital categories, $38.6 \%$ of the respondents in private secondary, $80 \%$ of those in government secondary and $29 \%$ of those in government tertiary hospital reported so. There was no observed association between pains in the knee region and health facility type ( $\mathrm{p}=0.344)$, as well as among the various hospital categories $(\mathrm{p}=0.073)$ (Table 8$)$.

Respondents (32\%) reported that they suffered from pains in the ankle/foot region while carrying out their job tasks (Figure 5). Among the various hospital categories, 28.6\% of respondents in the private secondary, $80 \%$ of respondents in the government secondary and $25.8 \%$ of respondents in the government tertiary hospitals reported that they suffered from pains in the ankle/foot region while carrying out their job tasks. No association was observed between pains in the ankle/foot region and health facility type $(\mathrm{p}=0.230)$, as well as among the various hospital categories $(\mathrm{p}=0.052)$ (Table 8).

Majority of all respondents $(28.3 \%)$ reported that each episode lasted two to three days (Figure 6). However, among the various hospital categories, $38.5 \%$ of respondents in the private secondary, $20 \%$ of respondents in the government secondary and $25 \%$ of respondents in the government tertiary hospitals reported so.

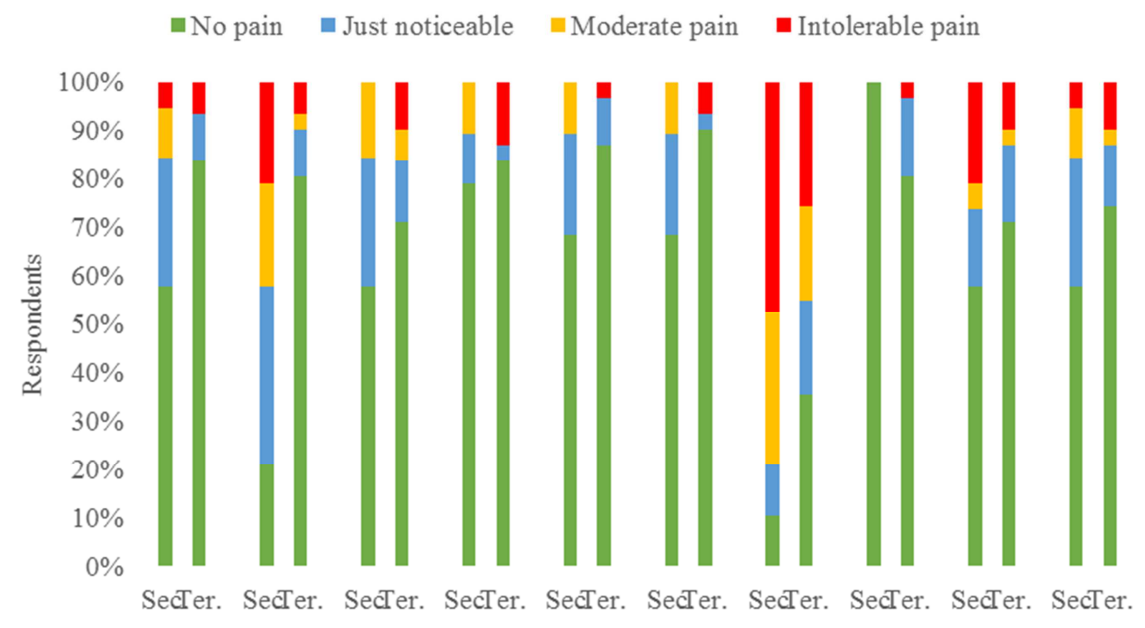

Figure 5. Musculoskeletal complaints and severity of pain among respondents.

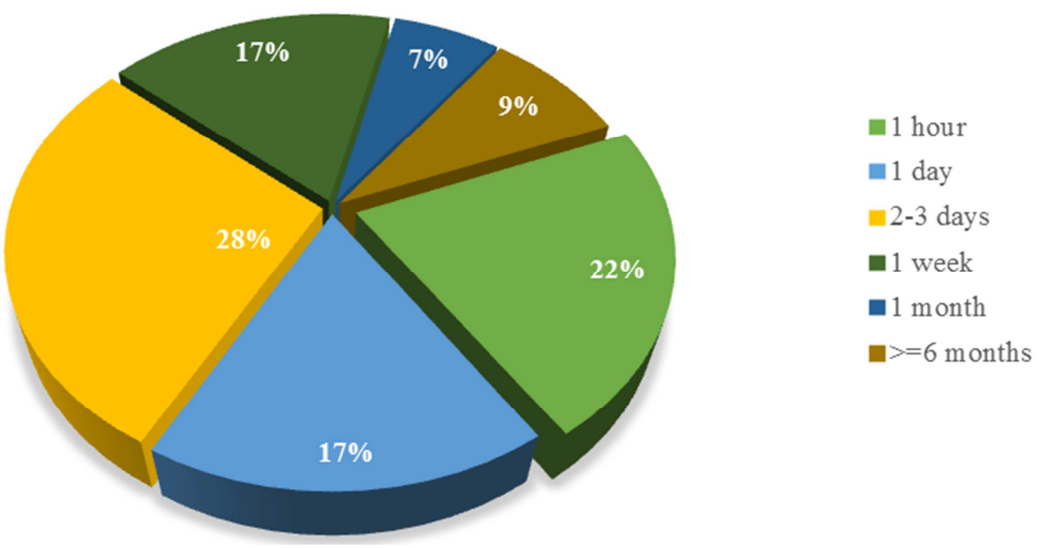

Figure 6. Length of each episode of musculoskeletal pain. 
Table 8. Measure of association among health facility indices and presence of musculoskeletal complaints.

\begin{tabular}{lllll}
\hline \multirow{2}{*}{ Body Area } & \multicolumn{2}{l}{ Type of health facility } & Hospital category & P-value \\
\cline { 2 - 5 } & $\mathbf{X}^{\mathbf{2}}$ & P-value & $\mathbf{X}^{\mathbf{2}}$ & 0.010 \\
\hline Neck & 4.131 & 0.042 & 9.196 & 0.000 \\
Shoulder & 17.173 & 0.000 & 18.173 & 0.305 \\
Upper Back & 0.897 & 0.344 & 2.375 & 0.398 \\
Elbow/Fore Arm & 0.193 & 0.660 & 1.844 & 0.002 \\
Wrist/Hand & 2.568 & 0.109 & 12.512 & 0.001 \\
Fingers & 3.828 & 0.050 & 14.607 & 0.122 \\
Lower Back & 3.814 & 0.051 & 4.204 & 0.124 \\
Hip/Thigh & 4.179 & 0.041 & 4.179 & 0.073 \\
Knee & 0.897 & 0.344 & 5.240 & 0.052 \\
Ankle/Foot & 1.438 & 0.230 & 5.916 & \\
\hline
\end{tabular}

\subsection{Other Health-Related Information}

Respondents $(76 \%)$ reported that they underwent a preemployment medical examination, however among the various hospital categories, $64.3 \%$ of the respondents in private secondary, $60 \%$ of those in government secondary and $83.9 \%$ of those in government tertiary hospital reported so (Table 9).

Respondents (38\%) reported that they were transferred from another department to the laundry department, including, $35.7 \%$ of the respondents in private secondary and $45.2 \%$ of those in government tertiary hospitals, however, they all reported that they did not undergo any medical examination prior to their transfer to the laundry department (Table 9).

Majority (56\%) of all the respondents reported that they did not know if they had been immunized against hepatitis, including, $71 \%$ of respondents in the government tertiary hospital. However, $71.4 \%$ of respondents in private secondary and $60 \%$ of those in government secondary hospitals reported that they had not been immunized against hepatitis. Only $9.7 \%$ of respondents in the government tertiary hospital affirmed that they had been immunized against hepatitis (Table 9).

Majority $(96 \%)$ of all the respondents reported that they did not have routine medical check-ups, while $54 \%$ of all respondents had visited a medical center in less than six months, with illness reported as the purpose of these medical visits $(89.7 \%)$ (Table 9).

Respondents (84\%) who have had one or more workplace accidents and injuries did not report any of them to the supervisor or administrator, including, all the respondents in private secondary, $80 \%$ of those in government secondary and $80 \%$ of those government tertiary hospitals, citing necessity as the major reason $(87 \%)$ for failure to report workplace accidents and injuries (Table 9).

Table 9. Other health-related information.

\begin{tabular}{|c|c|c|c|c|c|c|c|c|}
\hline \multirow{2}{*}{ Description of variables } & \multicolumn{2}{|l|}{ PS } & \multicolumn{2}{|c|}{ GS } & \multicolumn{2}{|l|}{ GT } & \multicolumn{2}{|c|}{ Total } \\
\hline & $\mathbf{n}$ & $\%$ & $\mathbf{n}$ & $\%$ & $\mathbf{n}$ & $\%$ & $\mathbf{n}$ & $\%$ \\
\hline \multicolumn{9}{|c|}{ Pre-employment medical examination } \\
\hline No & 5 & 35.7 & 2 & 40.0 & 5 & 16.1 & 12 & 24.0 \\
\hline Yes & 9 & 64.3 & 3 & 60.0 & 26 & 83.9 & 38 & 76.0 \\
\hline \multicolumn{9}{|c|}{ Transferred to laundry department } \\
\hline No & 9 & 64.3 & 5 & 100 & 17 & 54.8 & 31 & 62.0 \\
\hline Yes & 5 & 35.7 & 0 & 0 & 14 & 45.2 & 19 & 38.0 \\
\hline \multicolumn{9}{|c|}{ Medical examination prior to transfer } \\
\hline No & 5 & 100 & - & - & 14 & 100 & 19 & 100 \\
\hline \multicolumn{9}{|l|}{ Hepatitis immunization } \\
\hline No & 10 & 71.4 & 3 & 60.0 & 6 & 19.4 & 19 & 38.0 \\
\hline Yes & 0 & 0 & 0 & 0 & 3 & 9.7 & 3 & 6.0 \\
\hline Do not know & 4 & 28.6 & 2 & 40.0 & 22 & 71.0 & 28 & 56.0 \\
\hline \multicolumn{9}{|l|}{ Routine medical checks } \\
\hline None & 14 & 100 & 3 & 60.0 & 31 & 100 & 48 & 96.0 \\
\hline Monthly & 0 & 0 & 1 & 20.0 & 0 & 0 & 1 & 2.0 \\
\hline Quarterly & 0 & 0 & 1 & 20.0 & 0 & 0 & 1 & 2.0 \\
\hline \multicolumn{9}{|l|}{ Latest medical center visit } \\
\hline$<6$ months & 12 & 85.7 & 3 & 60.0 & 12 & 38.7 & 27 & 54.0 \\
\hline 6 months- 1 year & 2 & 14.3 & 1 & 20.0 & 5 & 16.1 & 8 & 16.0 \\
\hline $1-3$ years & 0 & 0 & 0 & 0 & 4 & 12.9 & 4 & 8.0 \\
\hline Cannot remember & 0 & 0 & 1 & 20.0 & 10 & 32.3 & 11 & 22.0 \\
\hline \multicolumn{9}{|l|}{ Purpose of medical visit } \\
\hline Routine medical check & 1 & 7.1 & 1 & 25.0 & 2 & 9.5 & 4 & 10.3 \\
\hline Illness & 13 & 92.9 & 3 & 75.0 & 19 & 90.5 & 35 & 89.7 \\
\hline \multicolumn{9}{|l|}{ Accidents/injuries reporting } \\
\hline Never & 5 & 100 & 4 & 80.0 & 12 & 80.0 & 21 & 84.0 \\
\hline Sometimes & 0 & 0 & 1 & 20.0 & 1 & 6.7 & 2 & 8.0 \\
\hline
\end{tabular}




\begin{tabular}{|c|c|c|c|c|c|c|c|c|}
\hline \multirow{2}{*}{ Description of variables } & \multicolumn{2}{|l|}{ PS } & \multicolumn{2}{|c|}{ GS } & \multicolumn{2}{|l|}{ GT } & \multicolumn{2}{|c|}{ Total } \\
\hline & n & $\%$ & n & $\%$ & n & $\%$ & n & $\%$ \\
\hline Always & 0 & 0 & 0 & 0 & 2 & 13.3 & 2 & 8.0 \\
\hline \multicolumn{9}{|c|}{ Reason for not reporting accidents/injuries } \\
\hline Not necessary & 5 & 100 & 4 & 80.0 & 11 & 84.6 & 20 & 87.0 \\
\hline Not available & 0 & 0 & 1 & 20.0 & 1 & 7.7 & 2 & 8.7 \\
\hline Reports not considered & 0 & 0 & 0 & 0 & 1 & 7.7 & 1 & 4.3 \\
\hline
\end{tabular}

where; PS=Private Secondary,

$\mathrm{GS}=$ Government Secondary, and

GT $=$ Government Tertiary

\section{Discussion}

\subsection{Socio-Demographic Characteristics}

Though the study population was largely female, as was also the case among respondents in the secondary healthcare facilities, the female to male ratio among those in the tertiary healthcare facility was almost equal. This observation in the tertiary healthcare facility may be as a result of the complexities in the healthcare laundry department that makes certain tasks more suited for females and others for the males, hence, the employment of a division of labor system that is gender-dependent. Likewise in the secondary healthcare facilities, females were observed to be more in number than males because the laundry operation is carried out manually, and with the notion and belief that females wash better than males, leaving the males to carrying out only the tasks of ironing and supervising.

This observation is in stark contrast to those made by Kumar et al. who noted in his study that workers in the tertiary healthcare laundry were more males than females, stating further that the observed difference was because the activities in the laundry department included more physical activities fitting for the male gender [45].

Furthermore, respondents in the tertiary healthcare laundry were observed to have received a higher level of education than their counterparts in the secondary health facilities. This may be explained by the washing process in the laundry, which is basically mechanized in the tertiary healthcare facility and require a higher level of education to operate, as opposed to that of the secondary health facility, where it is basically carried out manually and does not require a high level of education to undertake.

Also, workers in the tertiary hospital were observed to have worked longer in the healthcare laundry than their counterparts in the secondary hospitals and hence, had more work experience.

\subsection{Job Tasks of Respondents}

As observed in the study, almost all the workers in the secondary hospitals were involved in all the job tasks in the laundry process, except in the ironing of washed and dried laundry, which was only carried out by the males, as opposed to observations in the tertiary hospital where different groups of workers undertook a set of tasks, employing a division of labor system.

\subsection{Exposure of Respondents to Hazards in the Hospital Laundry}

The workers were exposed to a range of occupational hazards prevalent in the laundry department as previously observed by Kumar et al [45].

Majority of respondents in both secondary and tertiary health facilities alike reported that they came across sharps in the past year while carrying out their job tasks. Pyrek noted that airborne transmission notwithstanding, the real threat posed by contaminated linen is avoiding injuries from sharps, as laundry workers are constantly exposed to sharps which are usually hidden in contaminated laundry brought in from the wards and operating theatre [16].

While all the respondents in the secondary health facility reported that they did not carry out their job tasks in a comfortable posture, the majority of respondents in the tertiary health facility reported otherwise. This may be due to the laundering process in the secondary health facility, which is basically done manually, resulting in greater movement of the body as opposed to being done mechanically in the tertiary health facility with less body twisting and movement. Muslim et al. showed in a research that in every single activity of laundry workers in Indonesia, the positions were not ergonomic. Based on the posture assessment in the research, they concluded that there was a need for improvement in the laundry workers' posture [42].

Majority of respondents in both secondary and tertiary health facilities alike reported that they were able to see details of their workplace clearly while carrying out their job tasks and therefore were not exposed to hazards associated with illumination. This in contrast with a study by Imam et al. in a tertiary hospital in Egypt, who reported that majority of the support workers (non-health service providers) could not see without straining their eyes [49].

About half of respondents in the tertiary health facility reported that they were unable to communicate easily while carrying out their job tasks as a result of exposure to noise, unlike respondents in the secondary health facility, who all reported otherwise. This is as a result of the use of heavy machinery in the laundering process in the tertiary health facility and is supported by Imam et al. who observed that noise levels were above the standard of OSHA in the laundry of a tertiary hospital in Egypt [49].

Almost all of the respondents in the secondary health facility reported that they made use of chemicals while carrying out their job tasks, as opposed to about half of the 
respondents in the tertiary health facility. This is because almost all of the workers in the secondary health facility were involved in the washing tasks, whereas only a group of workers in the tertiary were involved in the task which was mechanized and required an understanding of the machine's technical operation. Sukumar and Karthiga in 2014, observed that healthcare workers are exposed to a wide variety of chemicals depending on the type of chemical products used [41].

About half of the respondents in the tertiary health facility reported that equipment which released heat was present in their work-space, whereas the majority of the respondents in secondary hospitals reported otherwise. This is because the major heat-emitting equipment in the secondary health facility is the pressing iron as compared to the driers and other heavy machinery in the tertiary health facility. Hasselhorn et al. noted that workers in hospital kitchens, laundry rooms, and sterilization units are the main groups that are exposed to heat-related hazard in a hospital setting [5].

\subsection{Exposure of Respondents to Biological Hazards in Linen}

Although all the respondents handled clean linen, only a number of them handled dirty and soiled linen. Exposure to the various pathogens is dependent on the type of linen handled, which is dependent on the job tasks carried out by the respondent. In a study by Kumar et al., it was also noted that the exposure to biological hazards varied depending upon the type of activity [45].

\subsection{Common Adverse Health and Safety Effects on Respondents}

A number of respondents reported that they had had at least one needle stick injury while carrying out their job tasks in the past year, with no difference observed between reports from secondary and tertiary health facilities. Hence, sharps injuries is still a major concern for healthcare workers in both secondary and tertiary hospital laundries alike. This is similar to report by Steed and Lettau who observed that overall, 39\% of hospital laundry workers had a history of at least one prior sharp injury [50].

Almost all of the respondents in secondary and tertiary health facilities alike reported that they had had musculoskeletal pains in at least one part of their body while carrying out their job tasks in the past year. This is as a result of repeatedly bending and extending of the back, squatting, stretching, and extending of the arms as well as other various body movements involved in the laundry operation, as was also previously observed by Kumar et al [45].

Only few respondents in the secondary and tertiary health facilities alike reported that they had had burns, electric shocks and hearing pains or disorder while carrying out their job tasks in the past year. In a report by Fontoura et al., tinnitus was reported by $29.47 \%$ [51]. Also, literature including Lopes et al. and Steinmetz et al. noted that tinnitus is a common symptom for those who work in noisy settings such as laundries [52, 53]. Furthermore, Hasselhorn et al. had previously noted that workers in laundry rooms are among the main groups that are exposed to heat-related hazard in a hospital setting [5].

A number of respondents in the tertiary health facility reported that they had had cuts or bruises while carrying out their job tasks in the past year, unlike those in the secondary health facility who all reported otherwise. This is as a result of the use of metal trolleys in the tertiary health facility for the transportation of laundry from the wards and operating theatre to the laundry room and back.

Over half of the respondents in the secondary health facility reported that they had slipped, tripped or fallen while carrying out their job tasks in the past year, unlike respondents in the tertiary health facility, where only a few of them reported so. This is similar to a report by Imam et al. who noted that $61.5 \%$ of support workers (non-health service providers) reported that the aisles and floors were in good condition and 53.8\% reported they were slippery [49].

In general, these findings are similar to those of Pyrek who noted that the most common accidents in industrial laundries involve chemical exposure, sharp objects left in soiled linen, slips from wet floors, exposure to pathogens in contaminated linen, among others [16], while Sukumar and Karthiga noted in their research among laundry workers that the majority of the respondents are affected by musculoskeletal disorder, slips from wet floors, chemical infections, and small scratch/bruise among others [41].

\subsection{Musculoskeletal Complaints and Severity of Pain Among Respondents}

Among the respondents in secondary health facility, the major musculoskeletal complaints in decreasing frequency were lower back and shoulder, followed by neck, upper back, knee and foot, whereas among the respondents in the tertiary health facility, the major musculoskeletal complaint was lower back, followed by those of the upper back and knee. In general, the respondents in the secondary health facility had a greater percentage of musculoskeletal complaints for all the body parts, except the hip/thigh region, where the percentage of complaints were higher among those in the tertiary health facility.

Also, majority of all respondents reported that each episode lasted two to three days, similar to reports by Ekawati, who further noted in his research that the most common complaints are of the upper body [54].

\subsection{Other Health-Related Information}

Majority of all the respondents reported that they underwent a pre-employment medical examination. However, as opposed to requirement by WHO [18], not all of the workers were examined before employment. Furthermore, all of the respondents who were transferred from another department to the laundry reported that they did not undergo any medical examination prior to the transfer. 
About half of all the respondents reported that they did not know if they had been immunized against hepatitis. Only a few respondents from the tertiary health facility affirmed that they had been immunized against hepatitis. This is in contrast to a similar study carried out in a tertiary health facility which reported that all respondents were vaccinated against hepatitis B [55].

Almost all of the respondents reported that they did not have routine medical check-ups, while about half of all respondents had visited a medical center in less than six months. This is in sharp contrast with a study by Kumar et al., who reported that all the laundry workers did have a periodic health appraisal during which they were examined and referred to respective specialties for free consultations [45].

Almost all of the respondents who have had one or more workplace accidents and injuries did not report any of them to the supervisor or administrator with majority of them of the opinion that it was unnecessary. However, Pyrek noted that a recommended step in ensuring a safer workplace includes encouraging reporting and elimination of workplace hazards. He further noted that this involves creating a blamefree environment for reporting injuries/accidents and injury hazards, explaining that healthcare personnel who know that management will discuss problems in an open and blame-free manner are more likely to report hazards [16].

\section{Conclusions}

Various hazards were identified in all the health facilities studied, with laundry workers exposed to these hazards. However, the exposures of laundry workers in the tertiary health facility to occupational hazards in their work place is significantly different from that of those in the secondary health facilities. Furthermore, it appeared mechanization played a major role in exposing laundry workers to hazards in the tertiary than in the secondary health facilities.

Also, the most common workplace injuries or illnesses reported by the hospital laundry workers were sharps injury, musculoskeletal pain, hearing disorder, burns, electric shocks, slips, trips, or falls, and cuts or bruises.

It is recommended that secondary health facilities employ a division-of-labor system, where a number of workers carry out specific job tasks, rather than all of the workers carrying out all the different job tasks. This is expected to reduce the number of workers exposed to the hazards inherent in each job task. In addition, laundry workers should be frequently educated on the occupational health and safety risks associated with their occupation, while encouraging them to report workplace incidents and illnesses.

Furthermore, healthcare laundry workers should be required to undergo pre-employment medical examination as well as regular medical checks, while workers transferred from other departments to laundry department should also undergo medical examination. Also, it should be ensured that all of the laundry workers are immunized against hepatitis.

\section{Limitations}

a) Compared to the respondents in the tertiary healthcare facilities, most of those in the secondary healthcare facilities needed some help in providing responses to the questionnaire because they were not as literate and therefore may have resulted in some form of bias when explaining the question and noting their responses.

b) Five secondary healthcare facilities was compared with only one tertiary health facility, lacking suitable grounds for proper comparative analysis. Furthermore, the study population was not large enough to carry out more valid comparative analysis, although total sampling was used in the study. Hence, a need for further study with a wider coverage for a more robust and valid comparative analysis.

\section{Conflict of Interests}

There are no conflicts of interest.

\section{References}

[1] Ford M. T. and Tetrick L. E. (2011). Relations among occupational hazards, attitudes, and safety performance. Journal of Occupational Health Psychology 16 (1), 48-66.

[2] Tziaferi S. G., Sourtzi P., Kalokairinou A., Sgourou E., Koumoulas E. and Velonakis E. (2011). Risk assessment of physical hazards in greek hospitals combining staff's perception, experts' evaluation and objective measurements. Safety and Health at Work Journal 2 (3), 260-72.

[3] Ajayi A. D., Garba S. N., Abdul A. J. and Mfuh A. (2006). Use of protective devices and occupational hazards among nurses in ABUTH, Zaria. West-African Journal of Nursing 7 (1), 14.

[4] Bell J. L., Collins J. W., Tiesman H. M., Ridenour M., Konda S., Wolf L. and Evanoff B. (2013). Slip, trip, and fall injuries among nursing care facility workers. Workplace Health and Safety Journal 61 (4), 147-52.

[5] Hasselhorn H. M., Toomingas A. and Lagerstrom M., Occupational health for health care workers: A practical guide, Amsterdam: Elsevier Science B. V., 2001, pp. 1-113.

[6] Ugbebor J. N., Modern safety: Principles and practice, Ibadan: Vertex media, 2014, 180p.

[7] Pingle S. R., Occupational health, The Godrej House Magazine, 2005.

[8] Borg M. A. and Portelli A. (1999). Hospital laundry workers an at-risk group for hepatitis A. Occupational Medicine (London) 49, 448-450.

[9] Topf M. (2000). Hospital noise pollution: An environmental stress model to guide research and clinical interventions. Journal of Adv. Nurs. 31, 520-528.

[10] Pyrek K. M., Lessons in Linen: Following Aseptic Technique in the Laundry Department, Informa Exhibitions LLC., 2003. 
[11] Stonerock T., "Women and the labour market," in Professional burnout: Recent developments in theory and research. London, vol. 2010, Rutledge S., Maslach W. C. and Marek T., Eds. New York, 2004.

[12] World Health Organization (WHO), "Health worker occupational health," in Occupational Health - Health workers, vol. 2012, Geneva: WHO; 2010.

[13] Amosun A. M., Degun A. M., Atulomah N. O. S., Olanrewaju M. F., Aderibigbe K. A. (2011). Level of knowledge regarding occupational hazards among nurses in Abeokuta, Ogun state, Nigeria. Current Research Journal of Biological Sciences 3 (6), 586-590.

[14] J. M. Harrington, F. S. Gill, T. C. Aw, G. Applebey and C. P. Atwell, Occupational health, 4th ed., Oxford: Blackwell Pup, 2000, pp. 3-347.

[15] Russi M. B. and Howarth M. V., Occupational medicine in health care industry: Text Book of Clinical Occupational and Environmental Medicine, 2nd ed., USA: Elsevier Inc., 2005, $245 \mathrm{pp}$.

[16] Pyrek K. M., Infection Control Today: Preventing Sharps Injuries and Blood-borne Pathogen Exposures in the Healthcare Laundry, Informa Exhibitions LLC., 2015, 12pp.

[17] Keeffe E. B. (2004). Occupational risk for hepatitis A: A literature-based analysis. Journal of Clinical Gastroenterology $38,440-448$.

[18] World Health Organization (WHO), Universal precautions, including injection safety, Geneva: WHO, 2006.

[19] Orji E., Fasubaa O. and Onwudiegwu U. (2002). Occupational health hazards among health care workers in an Obstetric and Gynaecological unit of a Nigerian Teaching hospital. Journal of Obstetrics and Gynaecology 22, 75-78.

[20] World Health Organization (WHO), Aide memoire for a strategy to protect health workers from infection with blood borne viruses, Geneva: WHO, 2003.

[21] Gawkrodger D. J., Lloyd M. H. and Hunter J. A. (1986). Occupational skin disease in hospital cleaning and kitchen workers. Contact Dermatitis 15, 132-135.

[22] Stingeni L., Lapomarda V. and Lisi P. (1995). Occupational hand dermatitis in hospital environments. Contact Dermatitis 33, 172-176.

[23] Bello A., Quinn M. M., Perry M. J. and Milton D. K. (2009). Characterization of occupational exposures to cleaning products used for common cleaning tasks-a pilot study of hospital cleaners. Environmental Health 8, 11-21.

[24] J. Zock, M. Kogevinas, J. Sunyer, E. Almar, N. Muniozguren, F. Payo, J. Sanchez and J. M. Anto (2001). Asthma risk, cleaning activities and use of specific cleaning products among Spanish indoor cleaners. Scandinavian Journal of Work, Environment and Health 27, 76-81.

[25] J. Zock, M. Kogevinas, J. Sunyer, D. Jarvis, K. Toren and J. Anto (2002). Asthma characteristics in cleaning workers, workers in other risk jobs and office workers. European Respiratory Journal 20, 679-685.

[26] A. Karjalainen, R. Martikainen, J. Karjalainen, T. Klaukka and K. Kurrpa (2002). Excess incidence of asthma among Finish cleaners employed in different industries. European respiratory journal 19, 90-95.

[27] M. Kopferschmitt-Kubler, J. Ameille, E. Popin, A. Calastreng-crinquad, D. Vervloet, M. Bayeux-Dungladd and G. Pauli (2002). Occupational asthma in France: A 1-year report of the Observatorie National de Asthmes Professionnels Project. European Respiratory Journal 19, 84-89.

[28] M. Medina-Ramon, J. P. Zock, M. Kogevinas, J. Sunyer and J. M. Anto (2003). Asthma symptoms in women employed in domestic cleaning: a community based study. Thorax 58, 950954.

[29] M. Medina-Ramon, J. P. Zock, M. Kogevinas, J. Sunyer, Y. Torralba, A. Borrell, F. Burgos and J. M. Anto (2005). Asthma, chronic bronchitis, and exposure to irritant agents in occupational domestic cleaning: a nested case-control study. Occupational and Environmental Medicine 62, 598-606.

[30] M. Medina-Ramon, J. P. Zock, M. Kogevinas, J. Sunyer, X. Basagana, J. Schwartz, P. S. Burge, V. Moore and J. M. Anto (2006). Short-term respiratory effects of cleaning exposures in female domestic cleaners. European Respiratory Journal 27, 1196-1203.

[31] G. L. Delclos, D. Gimeno, A. A. Arif, K. D. Burau, A. Carson, C. Lusk, T. Stock, E. Symanski, L. W. Whitehead and J. P. Zock (2007). Occupational risk factors and asthma among health care professionals. American Journal of Respiratory and Critical Care Medicine 175, 667-675.

[32] E. Andersson, A. C. Olin, S. Hagberg, T. Nilsson and K. Toren (2003). Adult onset asthma and wheeze among irritant exposed bleachery workers. American Journal of Industrial Medicine 43, 532-538.

[33] Ashton I, Gill SF, Monitoring for health hazards at work, 3rd ed. Oxford (United Kingdom): Blackwell Science; 2000. p. 33-185.

[34] Gehanno J. F. and Ledosseur P., "Radiation problems in the health care professions, " in Occupational health for health care workers: A practical guide, Amsterdam: Elsevier Science B. V., 1999, pp. 144-151.

[35] Jefferies P, Clemett R. S. and Turner J. R. (1993). Radiation hazards during cobalt 60 plaque therapy for choroidal melanoma. Aust. N. Z. J. Ophthalmol. 21, 37-41.

[36] Christensen M. (2007). Noise levels in a general intensive care unit: a descriptive study. Nursing Critical Care 12, 188-197.

[37] Ryherd E. E., Waye K. P. and Ljungkvist L. (2008). Characterizing noise and perceived work environment in a neurological intensive care unit. J. Acoust. Soc. Am. 123, 747756.

[38] Tsiou C., Efthymiatos G. and Katostaras T. (2008). Noise in the operating rooms of Greek hospitals. J. Acoust. Soc. Am. $123,757-765$

[39] J. A. F. Curado, W. C. S. V. Rabelo, W. Alves, R. F. Perini and P. H. Siqueira (2001). The incidence of PAIR in a university hospital. Arq. Int. Otorrinolaringol. 5 (2), 113116.

[40] IJzelenberg W., Molenaar D. and Burdorf A. (2004). Different risk factors for musculoskeletal complaints and musculoskeletal sickness absence. Scandinavian Journal of Work Environment and Health 30 (1), 56-63. 
[41] Sukumar S. and Karthiga V. (2014). A Study on Laundry Workers Attitude towards Health Care Industry in Trichy City. International Journal of Scientific Research and Publication 4 (1), $1-8$.

[42] Muslim E., Nurtjahyo B. and Ardi R. (2011). Ergonomic analysis of the garment industry with posture evaluation index in the virtual environment. Makara Teknologi. 15 (1), 75-78.

[43] Health and Safety Executive-UK (HSE-UK), Research report 491: Cost benefit studies that support tackling musculoskeletal disorders, 2006.

[44] Tseko G. and Pilane C., The nurse-midwife and use of universal precautions at a health facility in Botswana: implications for nurse training, AIDS 2006 - XVI International AIDS Conference, 2006.

[45] Kumar M. S., Goud B. R. and Joseph B. (2014). A study of occupational health and safety measures in the Laundry Department of a private tertiary care teaching hospital, Bengaluru. Indian Journal Occupational Environment Medicine 18 (1), 13-20.

[46] Enwere O. O. and Diwe K. C. (2014). Knowledge, perception and practice of injection safety and healthcare waste management among teaching hospital staff in South East Nigeria: an intervention study. Pan African Medical Journal 17,218 .

[47] Ofili A., Asuzu M. and Okojie O. (2003). Knowledge and practice of universal precaution amongst nurses in Central Hospital, Benin City, Edo State, Nigeria. Nigeria Postgraduate Medical Journal 10, 26-31.

[48] DHHS-NIOSH Publication No. 97-117, Symptom Survey: Ergonomics Program, Page 87.
[49] M. E. Imam, R. M. Alazab, A. Abdel-Wahed, A. A. Ghandour and W. H. Elsaidy (2013). Risk Assessment of Physical Health Hazards in Al-Azhar University Hospital in New Damietta, Egypt. Egyptian Journal of Hospital Medicine 53, 1019-1035.

[50] Steed C. and Lettau L. (1995). Hepatitis B Infection and Sharp-Object Injuries in Hospital Laundry Workers. Adv. Exp. Prev. 1 (5), 1-3.

[51] Fontoura F. P., Gonçalves C. G. O., Lacerda A. B. M. and Coifman H. (2014). Noise Effects on Hospital Laundry Workers' Hearing. Rev. CEFAC. 16 (2), 395-403.

[52] A. C. L. Lopes, K. A. Otubo, T. C. Basso, E. J. I. Marinelli and J. R. P. Lauris (2009). Occupational hearing loss: Tonal Audiometry X Audiometry of high frequencies. Arq Int Otorrinolaringol. 3 (3), 293-299

[53] L. G. Steinmetz, B. S. Zeigelboim, A. B. Lacerda, T. C. Morata and J. M. Marques (2009). Characteristics of tinnitus in workers exposed to noise. Rev. Bras. Otorrinolaringol. 75 (1), 7-14.

[54] Ekawati I. W., The Influence of Work Posture To The Musculoskeletal Disorder On Laundry Workers In Tembalang Region, International Seminar and Workshop on Public Health Action, 2015.

[55] Manuel M., Daphnie L., D'cunha S. and Suresh S. (2015). A study to assess awareness on occupational health hazard among laundry workers. Muller Journal of Medical Science Research 6 (1), 40-44. 